\title{
Experimental Study on Main Physical Parameters Controlling Shear Strength of Unsaturated Loess
}

\author{
Wen-tong Tian $\mathbb{D}^{1,},{ }^{1,2}$ Jian-hua Dong $\mathbb{D}^{1},{ }^{1}$ Jun-jie Sun $\mathbb{D}^{3},{ }^{3}$ and Bo Yang $\mathbb{D}^{2}$ \\ ${ }^{1}$ School of Civil Engineering, Lanzhou University of Technology, Lanzhou, Gansu 730050, China \\ ${ }^{2}$ Key Laboratory of Loess Earthquake Engineering, Lanzhou Institute of Seismology, CEA, Lanzhou, Gansu 730000, China \\ ${ }^{3}$ College of Civil Engineering and Architecture, Wenzhou University, Wenzhou, Zhejiang 325035, China
}

Correspondence should be addressed to Jian-hua Dong; djhua512@163.com

Received 7 October 2020; Revised 9 December 2020; Accepted 16 December 2020; Published 8 January 2021

Academic Editor: Jian Xu

Copyright (c) 2021 Wen-tong Tian et al. This is an open access article distributed under the Creative Commons Attribution License, which permits unrestricted use, distribution, and reproduction in any medium, provided the original work is properly cited.

It is particularly important to study the strength of unsaturated loess, and its accurate determination is crucial to the stability analysis of soil slope and foundation and calculation of earth pressure. In order to reveal the control mechanism of physical parameters on the shear strength of unsaturated loess, the intact and remolded loess were used as the research object; sandy silt, quartz flour, and quartz sand were used as contrast; the systematic direct shear tests of unsaturated loess, sandy silt, and quartz sand under different conditions of water content, dry density, and clay content were carried out. The results show that the cohesion, internal friction angle, and shear strength of unsaturated loess piecewise functionally decrease with the increase of water content, its shear strength increases linearly with the increase of dry density, and its internal friction angle shows an upward quadratic function relation with the increase of clay content. The law results of comparing sandy silt, quartz flour, and quartz sand with loess considering water content and dry density are the same; therefore, the equation of shear strength of unsaturated loess is proposed for practical engineering reference, and by the first derivative analysis of the equation, it is feasible to determine the control proportion of the three parameters on the shear strength of unsaturated loess. A stage-like difference between the three control proportions is observed, depending on the combination variations of water content and clay content.

\section{Introduction}

Loess is the sediments formed in the quaternary period. China is the country with the most perfect loess topographic development, the most extensive distribution, and the largest area in the world. In the process of loess deposition, geological agent, generative environment, and material source are the unique factors that form the obvious structural characteristics of loess with multiple pores and weak cementation $[1,2]$. The Loess Plateau is the starting point of the construction of China's Silk Road Economic Belt. Meanwhile, with the comprehensive advancement of urbanization, various engineering problems will occur. The underground water level in these areas is relatively deep, and most of the loess is in an unsaturated state. Therefore, it is particularly important to study the strength of unsaturated loess, and its accurate determination is crucial to the stability analysis of soil slope and foundation and the calculation of Earth pressure [3].

In recent years, many scholars have carried out some researches on the shear strength of saturated loess based on different perspectives and methods and achieved phased research results, which have been applied in a certain range. Dang et al. [4] studied the correlation between the cohesion and shear strength of unsaturated loess and the matrix suction and gave the formula for calculating the critical matrix suction; Li et al. [5] studied the variation rules of matrix suction, cohesion, and internal friction angle under different water content and proposed the shear strength model of unsaturated loess; Fredlundet al. [6,7] studied the relationship between the matrix suction of soil mass and its shear strength; Yuan et al. [8], Hu et al. [9], Kayadelen et al. [10], Pujiastut et al. [11], and Lin et al. [12] conducted tests based on the newly developed direct shear apparatus for 
unsaturated soil and obtained the variation rules of matrix suction and shear strength of unsaturated loess. However, the measurement and calculation of matrix suction are complex and difficult to obtain [13]. In practical engineering, the water content or saturation value is very easy to determine. Zhang et al. [14] studied the change law of unsaturated soil strength with water content by replacing suction with water content; $\mathrm{Li}$ and Miao [15] studied the relationship between shear strength stress and deformation of loess in different deposition ages and different water content through laboratory and field tests. Sun et al. [16] proposed that differences in soil shear strength cover nonuniform differences in other physical parameters such as water content, density, and gradation.

In addition, scholars in China and abroad have carried out a large number of studies on the shear strength of loess. The research methods are mainly indoor direct shear test and triaxial test. The research objects are mainly intact loess and remolded loess [17-25], lignin [26], and lime-improved loess [27]. The research conditions are dry-wet cycle [28] and freeze-thaw cycle [29], which enrich the research results of loess shear strength.

From the current research results, it is seldom to study comprehensively the influence of different physical parameters on the shear strength of unsaturated loess. Based on this, the author intends to study this problem from a simple and fundamental perspective, that is, starting from the idea of "science advocates simplicity" [30], instead of considering how the internal forces share the total shear strength, only considering the control effect of the physical properties parameters of the soil on the shear strength; therefore, it is necessary to analyze the control factors and control mechanism of shear strength of unsaturated loess.

Three controlling physical parameters of shear strength of unsaturated loess are summarized, namely, water content, dry density, and clay content. In this paper, unsaturated loess including intact loess and remolded loess is taken as the research object, and sandy silt, quartz flour, and quartz sand are taken as a comparative test; that is, the control law of three parameters on the shear strength of unsaturated loess is analyzed through controlling variable method and the control proportion of each parameter is determined.

\section{Laboratory Test and Test Data}

2.1. Test Scheme. The $Q_{3}$ loess and sandy silt samples of the sixth terrace of Yellow River in Jiuzhou platform of Lanzhou, China, are used in the laboratory test. Sampling site and stratigraphic distribution are shown in Figure 1, soil layers from top to bottom are $Q_{3}$ loess, sandy silt, sand, and pebble layer, the sampling depth of $Q_{3}$ loess is $6 \mathrm{~m}$, and the sampling depth of sandy silt is $8 \mathrm{~m}$. In order to do a comparative study on the characteristics of loess, sandy silt and 400 mesh quartz flour with similar particle size composition were selected. In order to study the influencing factors of clay content, 2500 mesh quartz flour was selected as the clay mixing material, and 40-70 mesh quartz sand was selected to carry out the related test for studying the influence of particle size on shear strength. Quartz sand (flour) adopts quartz ore deposit as raw material, through the mechanical crushing, rolling, washing screening, drying screening, vibration grading, and other procedures, finally forming quartz sand (flour) of various mesh number. The comparison test materials are shown in Figure 2, and the basic physical properties of test soil are shown in Table 1.

The Master400 laser particle size analyzer was used to analyze the particle size of the test soil samples. The test results are shown in Figure 3. It can be seen that the particle size distribution of $Q_{3}$ loess is between sandy silt and 400 mesh quartz flour and the three particle size distributions are relatively close. The 2500 mesh quartz flour is mainly composed of clay particles, and 40-70 mesh quartz sand is mainly composed of sand particles, which meets the requirements of the comparative test.

In order to analyze the control factors and control mechanism, by which the shear strength of unsaturated loess is affected, a four-link strain-controlled direct shear apparatus was used to obtain the data of the samples' internal friction angle and cohesion under different physical parameters.

The sample preparation process is as follows: the intact loess sample is cut and implanted into the cutting ring, and the water content required for the test is controlled by wetting or drying. After the remolded loess, sandy silt and quartz powder samples were mixed with a certain water content; they were rammed into samples in a cutting ring and adjusted to the required water content by wetting and drying. 40-70 mesh quartz sand was directly rammed into samples in the instrument sample box. The test process is shown in Figure 4.

The quick shear method was adopted in the test, the direct shear test in accordance with "standard for geotechnical test method, GBT 50123-2019” [31], with a shear rate of $1.2 \mathrm{~mm} / \mathrm{min}$, and there are four samples in each group. All of the soil samples will be cut out in 3-5 minutes, and the vertical pressures were $100 \mathrm{kPa}, 200 \mathrm{kPa}, 300 \mathrm{kPa}$, and $400 \mathrm{kPa}$, respectively. During the test, when the gauge pointer in the dynamometer does not move forward or there is an obvious backswing, it means that the sample has been cut out; it stops when the shear deformation reaches $4 \mathrm{~mm}$, but if the gauge pointer continues to increase after the shear displacement reaches $4 \mathrm{~mm}$, the shear deformation should reach the maximum shear value of the instrument of $6 \mathrm{~mm}$. During the categorization of the test data according to the Mohr-Coulomb criterion, the peak strength of the sample under each stage of pressure is taken from the peak point on the stress-strain curve. If there is no obvious peak point on the drawn stress-strain curve, then the strength value corresponding to the shear displacement of $4-6 \mathrm{~mm}$ is adopted according to the actual test data.

2.1.1. By Setting Different Water Content. We used intact loess and remolded loess in the direct shear test. In the test, the dry density was controlled to the same value, the dry density of intact loess was almost equal, and the water content of the soil samples was controlled to be $0 \%, 5.8 \%$, $10 \%, 15 \%, 20 \%, 25 \%$, and $35 \%$. During the test, when the 

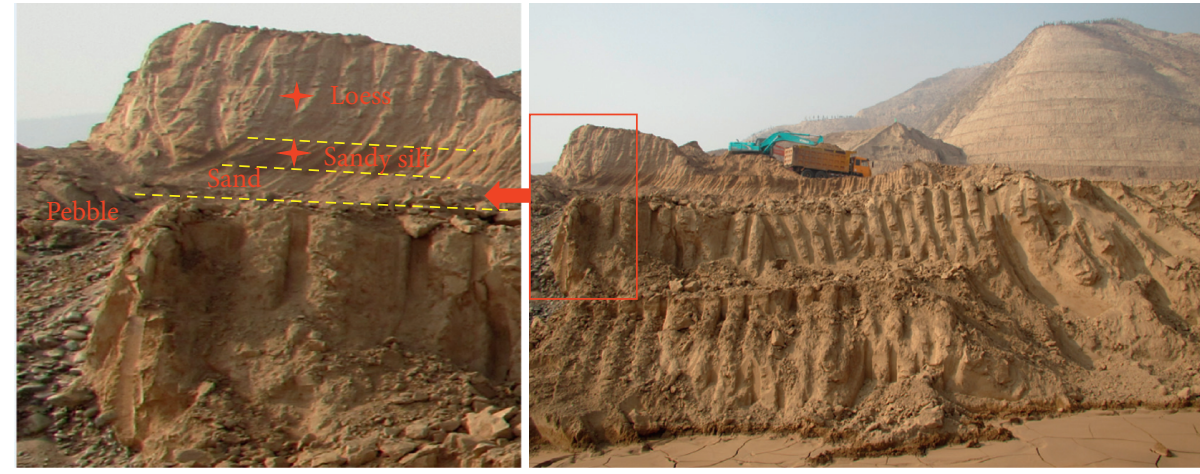

Figure 1: Photograph of sampling site and stratigraphic distribution of loess and sandy silty.

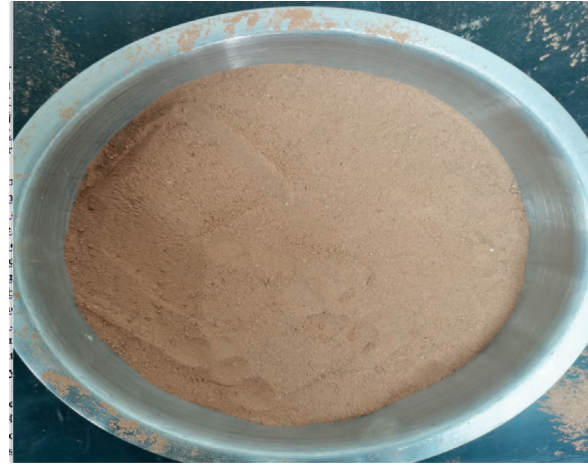

(a)

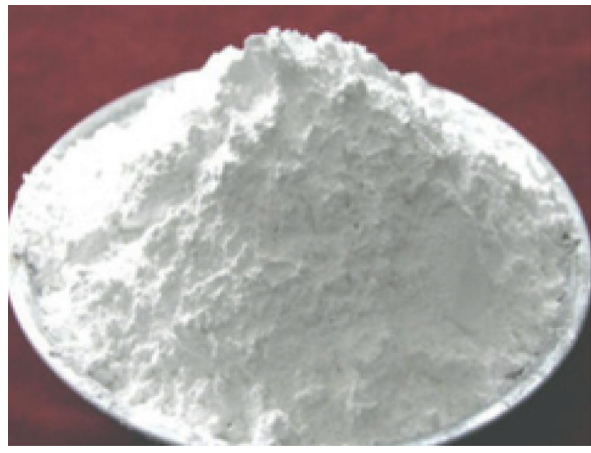

(c)

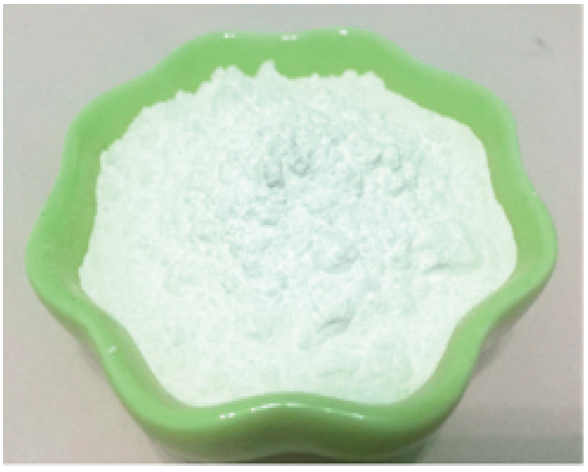

(b)

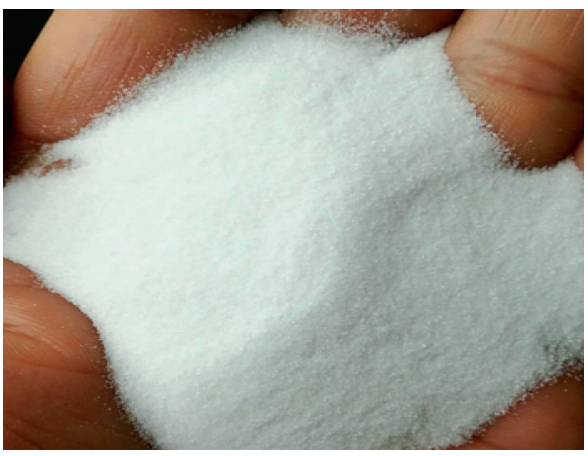

(d)

Figure 2: Comparison of test materials. (a) Sandy silt. (b) 400 mesh quartz flour. (c) 2500 mesh quartz flour. (d) 40-70 mesh quartz sand.

TABLE 1: Basic physical properties of test soil.

\begin{tabular}{lcccc}
\hline Type of soil & Specific gravity & Liquid limit (\%) & Plastic limit (\%) & Plasticity index \\
\hline Loess & 2.72 & 24.5 & 14.6 & - \\
Sandy silt & 2.69 & - & - & - \\
Quartz flour & 2.65 & - & - & - \\
\hline
\end{tabular}

gauge pointer in the dynamometer does not move forward or there is an obvious swing back, it indicates that the soil sample has been cut out. Table 2 shows the physical parameters and the direct shear test results of intact and remolded loess under different water content conditions.
2.1.2. By Setting Different Dry Density. We prepared remolded $Q_{3}$ loess and sandy silt samples with different dry densities, sandy silt was used for the comparative test, water content is set to $0 \%$ and $10 \%$, and the same direct shear tests as mentioned above were carried out. The physical 


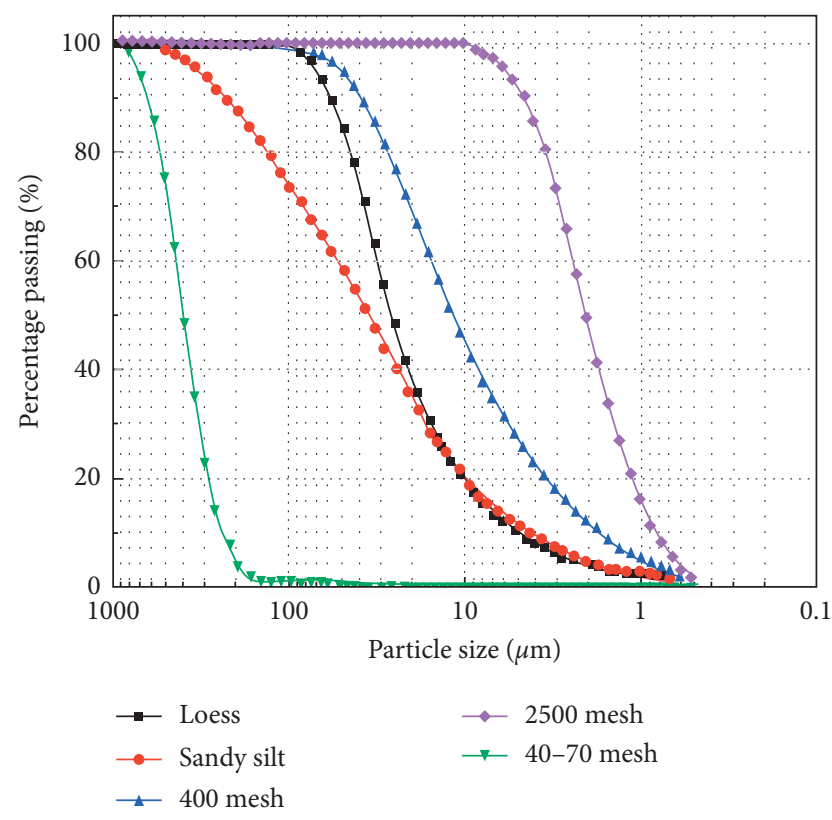

FIGURE 3: Grain size accumulation curve.

parameters and direct shear test results of remolded loess and sandy silt are shown in Table 3.

2.1.3. By Setting Different Clay Content. In the experiment, we added clay contents with the quantity of $3 \%, 5 \%, 10 \%$, $20 \%, 25 \%, 30 \%$, and $40 \%$ of the total mass into the sandy silt separately, and corresponding compensative amount of 2500 mesh quartz flour was also added, to ensure the dry density consistency of the clay content evenly mixed soil samples, with the intension of eliminating the influence of dry density onto the soil shear strength. And the same direct shear tests as mentioned above were carried out. The basic physical properties' parameters and the direct shear test results of the soil samples tested were shown in Table 4.

2.1.4. Comparative Experiments of Quartz Sand and Quartz Flour. In order to prove the results of unsaturated $Q_{3}$ loess and sandy silt, we applied some direct shear tests 40-70 quartz sand and 400 mesh quartz flour to make a contrast. The physical parameters and direct shear test results are shown in Table 5.

\section{Analysis Results and Discussions}

3.1. Influence of Water Content on Shear Strength of Unsaturated Loess. Figures 5 and 6 show the relationship between water content and internal friction angle, water content and cohesion, water content and shear strength of intact loess, and remolded loess.

It can be seen from Figure 5 that, with the increase of water content of intact loess and remolded loess, their internal friction angle has gradually decreased, the internal friction angle of remolded loess with the same water content is smaller than intact loess, and with the increase of water content, the internal friction angle of remolded loess and intact loess has the same decreasing trend; that is, the trend changes of two curves are similar, and the internal friction angle decreases rapidly when the water content is less than $10 \%$ and decreases slowly when the water content is greater than or equal to $10 \%$; moreover, the internal friction angle of two-phase has a linear reduction. The reason is that the increase of water content raises the flowing water in the soil sample; it promotes the sliding and reduces the friction force and mechanical interlocking force between soil particles; when the water content increases, its rate of reduction will slow down. With the increase of water content, the internal friction angle of two kinds of loess samples also has a decreasing trend; when the water content grows more than $10 \%$, its rate of reduction will slow down. With the increase of water content, the internal friction angle and cohesion of soil gradually reduced, so its shear strength also decreases gradually with the increase of water content. Due to the special water sensitivity of loess, it can be seen from Figures 5 and 6 that, under the same water content and dry density, the shear strength of remolded loess is less than the intact loess; because the intact loess has higher structural properties, its resistance to external force damage is higher, while the structure of remolded loess is relatively loose, so the shear strength of intact loess is higher than remolded loess [18].

According to the test results, the shear strength of two kinds of loess under every water content was calculated, when the normal stress is $100 \mathrm{kPa}$, we calculated the relationship between water content and shear strength by using the least square method, and their quantitative relation is shown in Figure 6. So, we can divide the change of shear strength of loess with the increase of water content into two stages: first, it decreases in a linear function and then decreases in a power function, and the rate of shear strength decreases when the increase of water content slows down. According to the fitting relationship between shear strength and water content in Figure 6, the following formula can be given:

$$
\begin{aligned}
& \tau=a w+b,\left(w<w_{0}\right), \\
& \tau=a^{\prime} w^{-b^{\prime}},\left(w \geq w_{0}\right) .
\end{aligned}
$$

Here, $w_{0}, a, b, a^{\prime}$, and $b^{\prime}$ are test parameters.

Equations (1) and (2) are used to express the shear strength of unsaturated loess with water content.

\subsection{Influence of Dry Density on Shear Strength of Unsaturated} Loess. The compaction degree of soil is mainly evaluated by the void ratio, while the void ratio of soil is only related to the dry density, and the compaction degree of soil is closely related to the shear strength. Therefore, to study the shear strength of soil, it is necessary to study the influence of dry density on it. Figure 7(a) shows the variation curve of the dry density-internal friction angle of remolded loess and sandy silt, and Figure 7(b) shows the variation curve of the dry density-cohesion of remolded loess and sandy silt.

According to the 8 curves in Figures 7(a) and 7(b), when the water content is a constant value, the internal friction angle and cohesion of remolded loess increase linearly with 

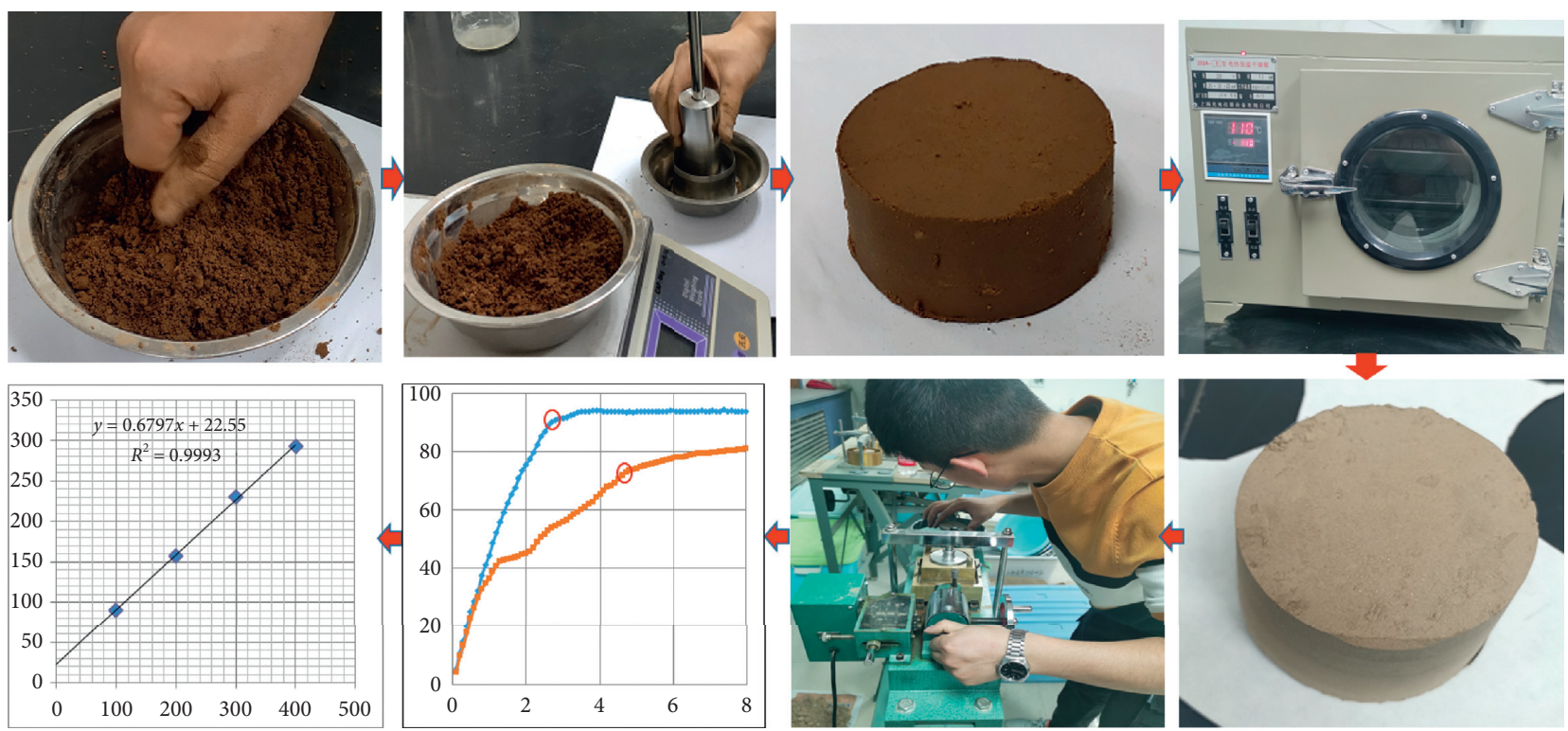

(a)

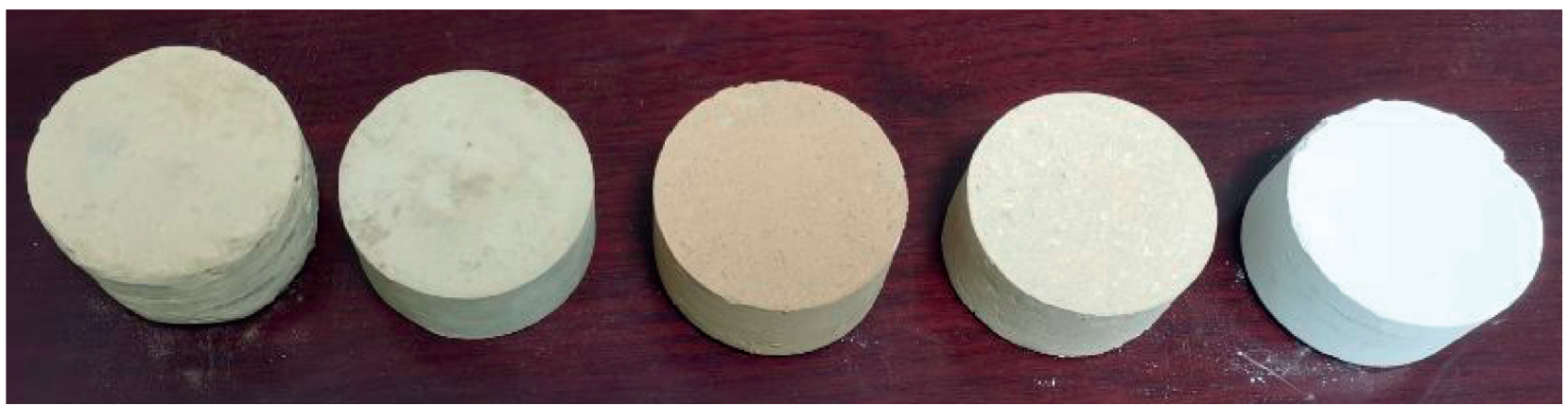

(b)

FIgURE 4: The photos of (a) the experimental process of direct shear test and (b) intact loess, remolded loess, sandy silt, sandy silt mixed with quartz flour, and quartz flour.

Table 2: Properties and direct shear test results of the loess.

\begin{tabular}{|c|c|c|c|c|c|}
\hline Water content $(\%)$ & Density $\left(\mathrm{g} / \mathrm{cm}^{3}\right)$ & Dry density $\left(\mathrm{g} / \mathrm{cm}^{3}\right)$ & Void ratio & Internal friction angle $\left({ }^{\circ}\right)$ & Cohesion $(\mathrm{kPa})$ \\
\hline \multicolumn{6}{|l|}{ Intact loess } \\
\hline 0 & 1.29 & 1.29 & 1.11 & 35.95 & 30.60 \\
\hline 5.8 & 1.35 & 1.27 & 1.14 & 29.31 & 25.20 \\
\hline 10 & 1.4 & 1.27 & 1.14 & 26.24 & 21.92 \\
\hline 15 & 1.472 & 1.28 & 1.125 & 24.81 & 18.70 \\
\hline 20 & 1.557 & 1.28 & 1.125 & 22.60 & 16.90 \\
\hline 25 & 1.642 & 1.28 & 1.125 & 19.42 & 13.80 \\
\hline 35 & 1.728 & 1.28 & 1.125 & 18.83 & 13.00 \\
\hline \multicolumn{6}{|l|}{ Remolded loess } \\
\hline 0 & 1.29 & 1.29 & - & 32.2 & 23.05 \\
\hline 5.8 & 1.35 & 1.27 & - & 25.8 & 20.15 \\
\hline 10 & 1.4 & 1.27 & - & 22.97 & 17.6 \\
\hline 15 & 1.472 & 1.28 & - & 20.89 & 15.12 \\
\hline 20 & 1.557 & 1.28 & - & 19.62 & 12.89 \\
\hline 25 & 1.642 & 1.28 & - & 16.80 & 11.64 \\
\hline 35 & 1.728 & 1.28 & - & 15.77 & 10.95 \\
\hline
\end{tabular}

the increase of dry density, which also indicates that the influence of dry density on shear strength is independent of water content. The internal friction angle and cohesion of remolded loess with the water content of $10 \%$ are smaller than dried remolded loess, which is consistent with the previous water content test results. Sandy silt is the same as 
TABLE 3: Properties of the remolded loess, sandy silt, and direct shear test results.

\begin{tabular}{|c|c|c|c|c|c|}
\hline Water content (\%) & Dry density $\left(\mathrm{g} / \mathrm{cm}^{3}\right)$ & Density $\left(\mathrm{g} / \mathrm{cm}^{3}\right)$ & Compaction degree & Internal friction angle $\left({ }^{\circ}\right)$ & Cohesion $(\mathrm{kPa})$ \\
\hline \multicolumn{6}{|l|}{ Remolded loess } \\
\hline 0 & 1.28 & 1.28 & - & 32.2 & 23.05 \\
\hline 0 & 1.37 & 1.37 & - & 35.1 & 27.3 \\
\hline 0 & 1.43 & 1.43 & - & 36.2 & 29.1 \\
\hline 0 & 1.51 & 1.51 & - & 37.4 & 30.7 \\
\hline 10 & 1.28 & 1.4 & - & 22.97 & 17.6 \\
\hline 10 & 1.37 & 1.5 & - & 24.55 & 19.8 \\
\hline 10 & 1.43 & 1.57 & - & 25.3 & 20.7 \\
\hline 10 & 1.51 & 1.66 & - & 26 & 21.6 \\
\hline \multicolumn{6}{|l|}{ Sandy silt } \\
\hline 0 & 1.638 & 1.638 & $90 \%$ & 28.8 & 7.5 \\
\hline 0 & 1.69 & 1.69 & $93 \%$ & 33.5 & 9.3 \\
\hline 0 & 1.75 & 1.75 & $96 \%$ & 36 & 11.2 \\
\hline 0 & 1.82 & 1.82 & $100 \%$ & 39.2 & 12.4 \\
\hline 10 & 1.638 & 1.8 & $90 \%$ & 22.6 & 3.8 \\
\hline 10 & 1.69 & 1.859 & $93 \%$ & 27.2 & 5.3 \\
\hline 10 & 1.75 & 1.925 & $96 \%$ & 29.8 & 6.47 \\
\hline 10 & 1.82 & 2 & $100 \%$ & 32.74 & 7.45 \\
\hline
\end{tabular}

TABle 4: Properties of sandy silt and direct shear test results.

\begin{tabular}{lcccc}
\hline Clay content $(\%)$ & Dry density $\left(\mathrm{g} / \mathrm{cm}^{3}\right)$ & Void ratio & Internal friction angle $\left(^{\circ}\right)$ & Cohesion $(\mathrm{kPa})$ \\
\hline 3 & 1.8 & 0.494 & 32.30 & 3.80 \\
5 & 1.8 & 0.494 & 29.45 & 3.75 \\
10 & 1.8 & 0.494 & 28.18 & 3.50 \\
20 & 1.8 & 0.494 & 27.44 & 3.40 \\
25 & 1.8 & 0.494 & 28.34 & 0.60 \\
30 & 1.8 & 0.494 & 34.20 & 4.75 \\
40 & 1.8 & 0.494 & & 7.85 \\
\hline
\end{tabular}

TABle 5: Quartz sand and quartz flour direct shear test results.

\begin{tabular}{|c|c|c|c|}
\hline Water content $(\%)$ & Internal friction angle $\left({ }^{\circ}\right)$ & Dry density $\left(\mathrm{g} / \mathrm{cm}^{3}\right)$ & Internal friction angle $\left({ }^{\circ}\right)$ \\
\hline \multicolumn{4}{|c|}{ 40-70 mesh quartz sand } \\
\hline 0 & 37.45 & 1.4 & 35.87 \\
\hline 5 & 34.98 & 1.5 & 37.45 \\
\hline 10 & 33.38 & 1.6 & 40.58 \\
\hline 15 & 31.2 & - & - \\
\hline 20 & 30.1 & - & - \\
\hline \multicolumn{4}{|c|}{400 mesh quartz flour } \\
\hline 0 & 39.83 & 1.4 & 38.11 \\
\hline 5 & 38.73 & 1.5 & 39.83 \\
\hline 10 & 37.56 & 1.6 & 42.09 \\
\hline 15 & 36.72 & - & - \\
\hline 20 & 35.98 & - & - \\
\hline
\end{tabular}

remolded loess; when water content changes, the internal friction angle and cohesion increase with the increase of dry density. However, the cohesion of sandy silt is very small, so its change value is very small, and the internal friction angle changes obviously. Under the normal stress of $100 \mathrm{kPa}$, the relationship between shear strength and dry density was calculated, as shown in Figure 8.

It can be seen from Figure 8 that, with the increase of dry density, the shear strength of soil increases linearly. Compared with the test results of sandy silt, we can find out the higher the compaction degree of soil is, the smaller the void ratio in the soil is; the soil particles are closer, and the degree of occlusion of particles is better then increases the surface friction resistance between soil particles, so the resistance overcome by shear failure force is greater at the same time, which is manifested in the greater internal frictional angle. For unsaturated loess, when the dry density of soil is higher, the dispersion will be lower, and the hydrophilic properties of soil are relatively weak. Because the surface of the soil particles is surrounded by the hydrated film, the decrease of water reduces the thickness of the hydrated film, which increases the cohesion. Therefore, the above two aspects work together to increase the dry density, and the shear strength of unsaturated loess is greater. 


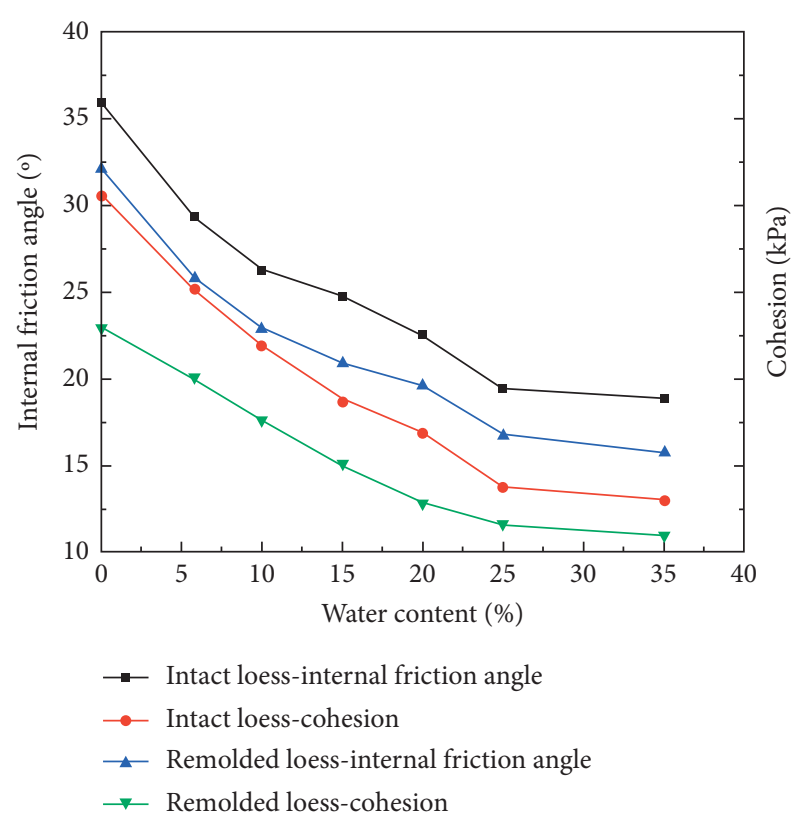

FIgURE 5: Relationship between internal friction angle, cohesion, and water content of intact loess and remolded loess.

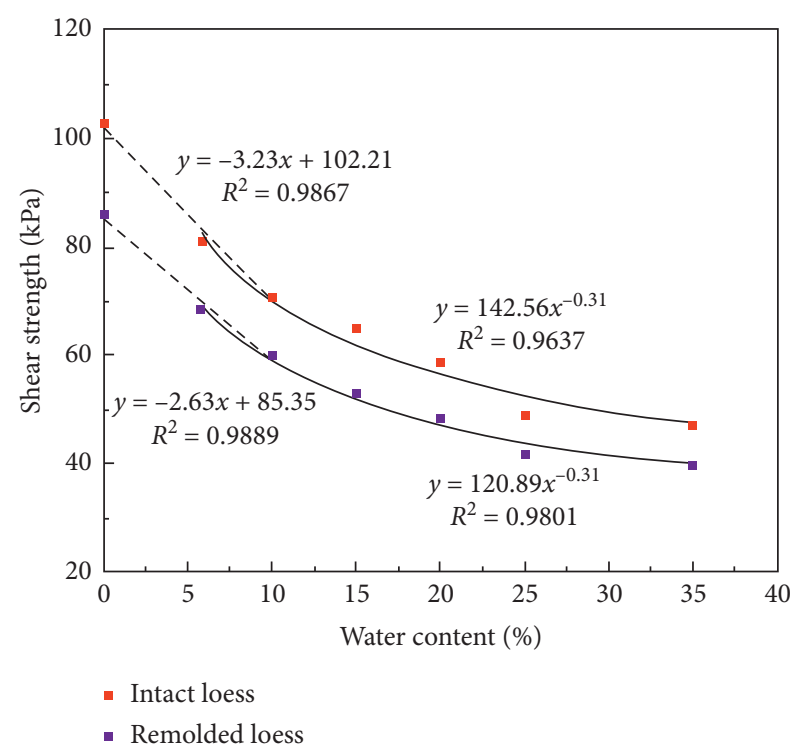

FIGURE 6: The water content and shear strength diagram of intact, remolded loess.

As can be seen from Figure 8, the linear relationship between shear strength and dry density can be expressed by the following equation:

$$
\tau=c \rho_{d}+d .
$$

Here, $c$ and $d$ are the test parameters.

\subsection{Influence of Clay Content on Shear Strength of Unsatu-} rated Soil. For cohesionless soil, its shear strength mainly depends on the internal friction angle. The internal friction angle is related not only to the degree of dispersion but also to the shape, particle size, and content of the clay in the soil. This part mainly studies the influence of different clay content on the shear strength of sandy silt; based on the test results, the possible reasons for the influence of clay content on shear strength are analyzed.

The relationship between the clay content and the internal friction angle is shown in Figure 9. It can be seen from Figure 9 that the internal friction angle gradually decreases with the increase of the clay content at the beginning and becomes the minimum when the clay content reaches about $24 \%$ and then gradually increases with the increase of the clay content.

It can be seen from the analysis that when clay content is less than $24 \%$, because the surface of 2,500 mesh quartz flour is very smooth, the quartz flour filled in the middle of the soil particles would act like a ball while the soil is sheared, which makes the soil particles easy to slip relatively. With the increase of clay content, the sliding trend becomes more and more obvious, so the internal friction angle of soil gradually decreases, and when the clay content is equal to $24 \%$, the internal friction angle reaches the minimum, and then the internal friction angle gradually increases with the increase of clay content. The author believes that, with the continuous increase of clay particles, it will fill between coarse particles gradually, and quartz flour particles will gradually become the role of clay particles. With the continuous increase of clay particles, the physical and chemical properties of clay surface are enhanced, flocculation is obvious, and the internal friction angle will gradually increase and increase faster. According to the relationship between the internal friction angle and clay content in Figure 9, the following equation can be given:

$$
\tau=\sigma \tan \left(e \eta^{2}+f \eta+g\right)
$$

Here, equation (4) is the equation of soil shear strength expressed by clay content, where $e, f$, and $g$ are the test parameters and $\eta(\%)$ is the clay content.

\subsection{Direct Shear Test Compared with Quartz Sand and Quartz} Flour. The structure of loess in nature is very complex. Therefore, if we want to study the influence of a certain factor on the shear strength of soil, the test results may not be particularly accurate. Therefore, the author would like to do some quartz sand and quartz flour tests to support the previous test results and study the shear strength relationship of different particle size soils; the characteristics of quartz sand and quartz flour are that their gradation, particle shape, and distribution are very uniform, so the processing consistency of test data is very high, which has certain reference significance for the study of the soil in nature.

The experimental results show that when the dry density is a constant value, the internal friction angle of quartz sand and quartz flour decreases with the increase of water content, and both of them show a linear trend (fitting as power function is also more consistent). On the contrary, when the water content is a constant value, the internal friction angle of quartz sand and quartz flour increases with the increase of dry density, and both of them show a linear trend. Under the 

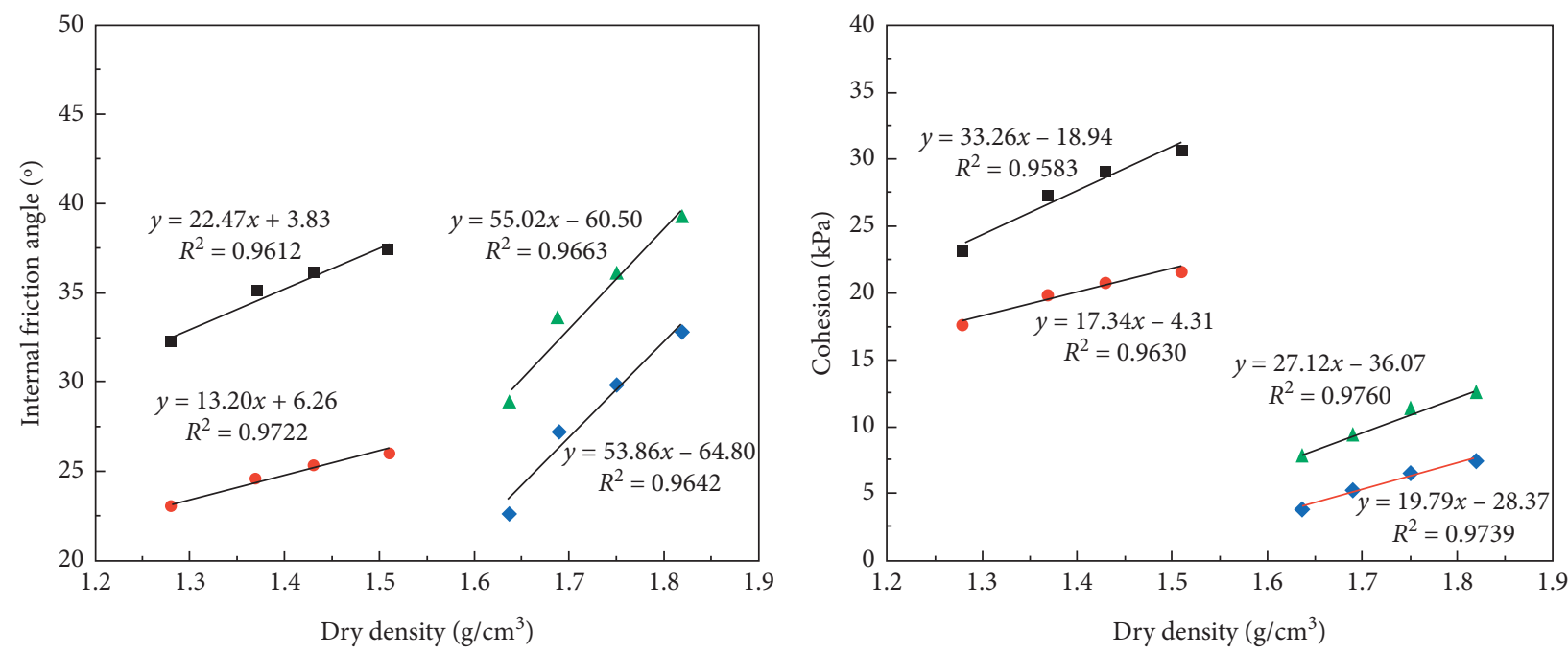

- Remolded loess-water content 0

- Remolded loess-water content $10 \%$

- Sandy silt-water content $10 \%$

- Sandy silt-water content 0

- Remolded loess-water content 0

- Remolded loess-water content $10 \%$

- Sandy silt-water content $10 \%$

\ Sandy silt-water content 0

(b)

Figure 7: (a) The dry density and internal friction angle diagram of remolded loess, sandy silt; (b) the dry density and cohesion of remolded loess, sandy silt.



- Remolded loess-water content 0

- Remolded loess-water content $10 \%$

- Sandy silt-water content $10 \%$

A Sandy silt-water content 0

Figure 8: Relationship between dry density and shear strength of remolded loess and sandy silt.

normal stress of $100 \mathrm{kPa}$, the linear equation fitting the water content and shear strength of quartz sand and quartz flour and the linear equation fitting the dry density and shear strength are shown in Figure 10(a) and Figure 10(b), the fitting coincidence index is very high, which is closely related to the standard structure of quartz sand and quartz flour, and the readings are more accurate due to homogeneity of its

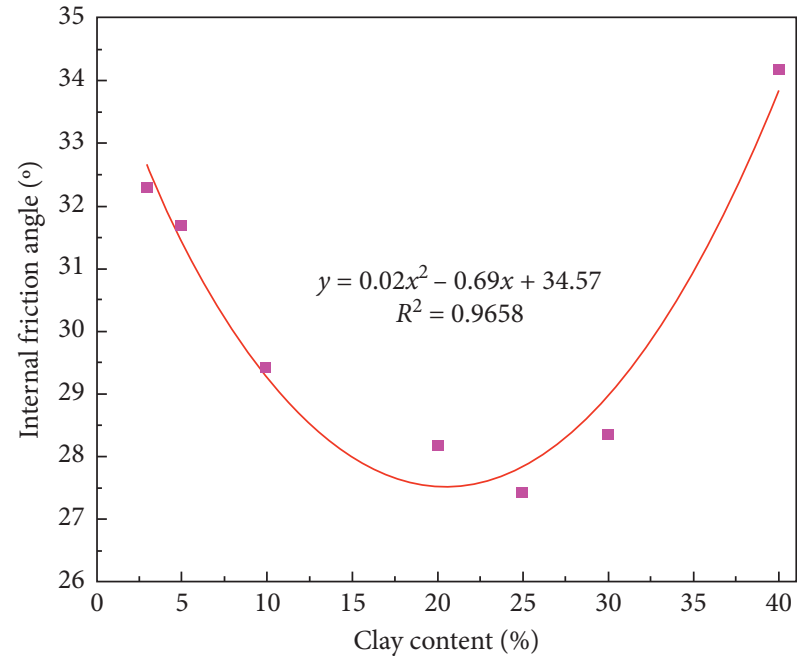

FIGURE 9: Relationship between clay content and internal friction angle.

texture during the test. The experimental results of water content and dry density of quartz sand and quartz flour are consistent with those of loess and sandy silt.

Because of the standardization of quartz sand and quartz flour, the soil samples prepared can be almost consistent, and other uncertain factors can be excluded, so the error is small; therefore, the shear strength of soils with different particle size soil can be analyzed by using the direct shear tests results of two different particle sizes of quartz sand and quartz flour. From the test results, we can find out that the 


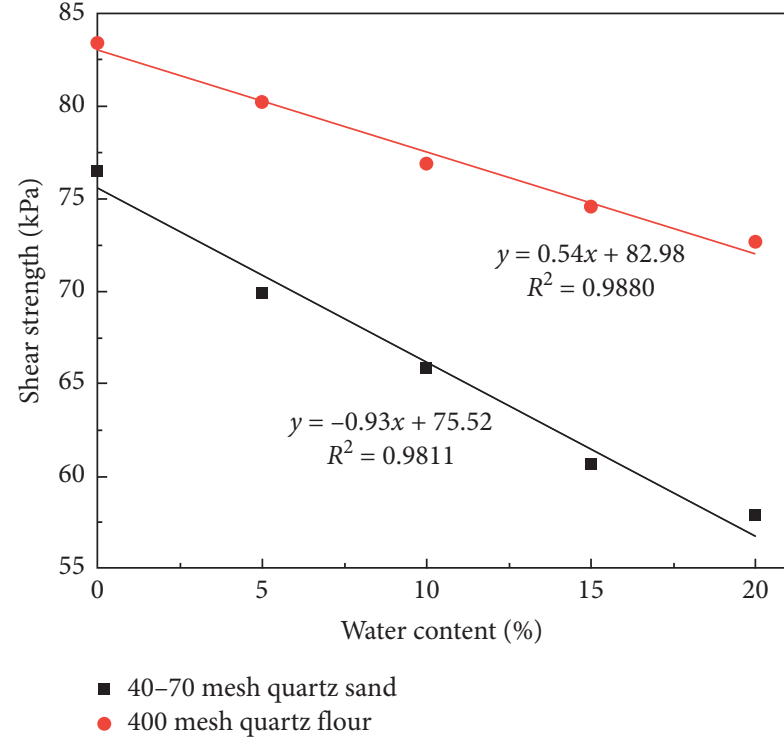

(a)

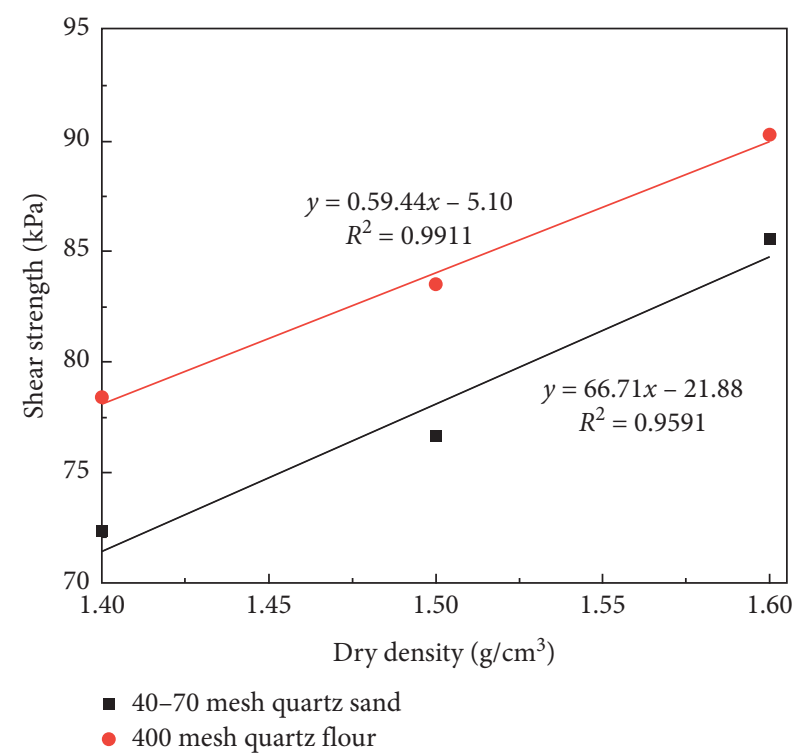

(b)

FiguRE 10: (a) Relationship between water content and shear strength of quartz sand/flour; (b) relationship between dry density and shear strength of quartz sand/flour.

internal friction angle of 400 mesh quartz flour is larger than that of 40-70 mesh quartz sand under the same water content and dry density. In analysis results, we can find out that 400 mesh quartz flour particle size is smaller, the combination between particles is more close under the same dry density, and the effective contact area between particles is large, so the greater the friction resistance, the higher the corresponding shear strength in the process of shear failure and resisting external force. The author thinks that this conclusion is also applicable to loess in nature.

\subsection{Quantitative Analysis of the Control Mechanism of Shear} Strength. As for the shear strength of unsaturated soil, the influencing factors are not simply one or two but are determined by the comprehensive factors in the formation process of soil. Like all things developed, several factors in this paper play a controlling role in the influencing factors of soil shear strength. By comparing and analyzing the test results of sandy silt, quartz sand, and quartz flour, the following shear strength formula containing the above control elements can be proposed for the influence of water content, dry density, and clay content on the shear strength of unsaturated loess.

In order to compare the influence degree of the three dominant factors of shear strength on shear strength, the change rate of the three functions can be calculated by derivation, and then the influence degree of the three functions on unsaturated loess can be analyzed qualitatively.

For water content, equations (1) and (2) are derived as follows:

$$
\begin{aligned}
& \dot{\tau}(w)=a\left(w<w_{0}\right), \\
& \dot{\tau}(w)=-a^{\prime} b^{\prime} w^{-b^{\prime}-1}\left(w \geq w_{0}\right) .
\end{aligned}
$$

For dry density, equation (3) is derived:

$$
\dot{\tau}\left(\rho_{d}\right)=c .
$$

For the clay content, Taylor series expansion of equation (4) is carried out first for convenience of comparison:

$$
\begin{aligned}
\tau & =\sigma \tan \left(e \eta^{2}+f \eta+g\right) \\
& =\tau\left(\eta_{0}\right)+\dot{\tau}\left(\eta_{0}\right)\left(\eta-\eta_{0}\right)+\frac{1}{2} \dot{\tau}\left(\eta_{0}\right)\left(\eta-\eta_{0}\right)+\cdots \\
& =\sigma \tan \left(e \eta_{0}^{2}+f \eta_{0}+g\right)+\sigma\left(2 e \eta_{0}+f\right)\left(\eta-\eta_{0}\right) \sec ^{2} \eta_{0}+\cdots
\end{aligned}
$$

For comparison, only the first two items are taken:

$$
\tau=\sigma \tan \left(e \eta_{0}^{2}+f \eta_{0}+g\right)+\sigma\left(2 e \eta_{0}+f\right)\left(\eta-\eta_{0}\right) \sec ^{2} \eta_{0} .
$$

The derivation is as follows:

$$
\dot{\tau}(\eta)=\sigma\left(2 e \eta_{0}+f\right)\left(\sec ^{2} \eta_{0}\right) .
$$

Because $\sigma=100 \mathrm{kPa}$,

$$
\dot{\tau}(\eta)=100\left(2 e \eta_{0}+f\right)\left(\sec ^{2} \eta_{0}\right) .
$$

So $\dot{\tau}(w), \dot{\tau}\left(\rho_{d}\right)$, and $\dot{\tau}(\eta)$ are compared to determine the control or influence degree of water content, dry density, and clay content on unsaturated loess.

According to the above test results and the coefficient calculation of the fitting formula, it can be concluded that when the water content is less than $27 \%$, the clay content is more than $12 \%$ and less than $28 \%$, the change of water content has the greatest impact on shear strength, the dry 
density takes second place, and the influence of the clay content is the least. When the water content is less than $27 \%$, the clay content is less than $12 \%$ or more than $28 \%$, the influence of the dry density is the least, and the influence difference between water content and clay content is negligible. When the water content is greater than $27 \%$ and the clay content is greater than $12 \%$ and less than $28 \%$, the dry density has the greatest influence on shear strength and the influence of the water content is not much different from clay content.

Therefore, the proportions of these three main control factors are related to the physical parameter content of the loess. When the water content is low, the change of water content has the greatest influence on the shear strength of unsaturated loess, which is related to its special water sensitivity. The change of dry density of high water content has the greatest influence on the shear strength of unsaturated loess. It shows that the influence of each factor has the characteristics of stages.

\section{Conclusion}

(1) When considering the control mechanism of unsaturated loess physical parameters on its shear strength, three main factors, namely, water content, dry density, and clay content, were selected. By experimental study, we find out that the above three parameters have a significant influence on the shear strength of unsaturated loess, and the variation of shear strength with the increase of a single factor is quite different.

(2) The relationship between shear strength loess and water content, dry density, and clay content of unsaturated loess is fitted, and the fitting equation is given. The results show that the relationship between shear strength and water content is a nonlinear decrease, which can be characterized by piecewise function; the relationship between shear strength and dry density increases linearly. Only the influence of the internal friction angle was studied in the experiment of controlling the change of clay content, and its relation with the clay content could be characterized by the quadratic function with opening upward.

(3) The experimental results of the water content and dry density of sandy silt, quartz sand, and quartz flour are consistent with those of loess. Therefore, the shear strength equation of unsaturated loess considering the above control factors can be used as a reference for practical engineering.

(4) The control mechanism and proportion of the three parameters are analyzed in a unified way, and the derivation analysis method of the shear strength equation proposed in this paper is feasible. The control proportion of the three parameters on the shear strength of unsaturated loess has different stages; that is, the proportion of each parameter is varied with the variation of water content and clay content.

\section{Data Availability}

The data used to support the findings of this study are available from the corresponding author upon request.

\section{Conflicts of Interest}

The authors declare that they have no conflicts of interest regarding the publication of this paper.

\section{Acknowledgments}

This research was funded by projects of Seismological Science and Technology Spark Program, CEA (no. XH18049SX), the Institute of Earthquake Forecasting, China Earthquake Administration (nos. 2017IESLZ06 and 2019IESLZ04), and the National Natural Science Foundation of China (nos. 51779234 and 51778275).

\section{References}

[1] T. S. Liu, Loess and the Environment, China Ocean Press, Beijing, China, 1985.

[2] X. Y. Lei, "Gap types and collapsibility of loess in China," Science in China, Series B, vol. 31, no. 12, pp. 1309-1316, 1987.

[3] J. Y. Chen and D. G. Fredlund, "Advance in research on shear strength of unsaturated soil," Rock and Soil Mechanics, vol. 24, no. s2, pp. 655-660, 2003.

[4] J. Q. Dang and J. Li, "Strength characteristics of unsaturated loess," Chinese Journal of Geotechnical Engineering, vol. 19, no. 2, pp. 59-64, 1997.

[5] Y. L. Li and H. F. Zhang, "Experimental study of triaxial test of undisturbed unsaturated loess," Rock and Soil Mechanics, vol. 29, no. 10, pp. 2859-2863, 2008.

[6] J. K. Gan, D. G. Fredlund, and H. Rahardjo, "Determination of shear parameters of an unsaturated soil using the direct shear test," Canadian Geotechnical Journal, vol. 25, no. 08, pp. 500-510, 1988.

[7] D. G. Fredlund and H. Rahardjo, Soil Mechanics for Unsaturated Soils, John Wiley and Sons, New York, NY, USA, 1993.

[8] Z. H. Yuan and W. K. Ni, "Study of shear strength of unsaturated and undisturbed loess based on suction stress," Journal of Hefei University of Technology, vol. 38, no. 5, pp. 648-653, 2015.

[9] S. X. Hu, Y. D. Zhou, and Z. H. Chen, "Test study on strength character of unsaturated and undisturbed loess," Rock and Soil Mechanics, vol. 26, no. 4, pp. 660-672, 2005.

[10] C. Kayadelen, M. A. Tekinsoy, and T. Taşkıran, "Influence of matric suction on shear strength behavior of a residual clayey soil," Environmental Geology, vol. 53, p. 891, 2007.

[11] H. Pujiastut and R. Ahmad, "The effect of matric suction on the shear strength of unsaturated sandy clay," International Journal of Geomate, vol. 14, no. 42, pp. 112-119, 2018.

[12] H. Z. Lin, G. X. Li, Y. Z. Yu et al., "Influence of matric suction on shear strength behavior of unsaturated soils," Rock and Soil Mechanics, vol. 28, pp. 1931-1936, 2007.

[13] H. Ling and Z. Z. Yin, "Unsaturated soil strength varies with water content," Chinese Journal of Rock Mechanics and Engineering, vol. 26, no. 7, pp. 1499-1503, 2007.

[14] M. H. Zhang, Y. L. Xie, and B. J. Liu, "Analysis of shear strength characteristics of loess during moistening process," Rock and Soil Mechanics, vol. 27, no. 7, pp. 1195-1200, 2006. 
[15] B. X. Li and T. D. Miao, "Research on water sensitivity of loess shear strength," Chinese Journal of Rock Mechanics and Engineering, vol. 25, no. 5, pp. 1003-1008, 2006.

[16] J. J. Sun, L. M. Wang, X. Q. Chen et al., "Critical influence parameters and magnitude estimation of dynamic residual strain of unsaturated loess," Earthquake Engineering and Engineering Dynamics, vol. 34, no. s1, pp. 936-940, 2014.

[17] Z. A. Gao, P. Li, J. J. Xiao et al., "Evaluation of shear strength of unsaturated loess using conventional direct shear test," Journal of Engineering Geology, vol. 28, no. 2, pp. 344-351, 2020.

[18] F. Wei, Z. H. Yao, Z. H. Chen et al., "Influence of structural properties on strength and yielding characteristics of unsaturated $Q_{3}$ loess," Rock and Soil Mechanics, vol. 36, no. 9, pp. 2551-2559, 2015.

[19] J. R. Zhang, J. Zhu, and W. J. Huang, "Crushing and fractal behaviors of quartz sand-gravel particles under confined compression," Chinese Journal of Geotechnical Engineering, vol. 36, no. 9, pp. 783-789, 2008.

[20] T. Gu, J. Wang, C. Wang, Y. Bi, Q. Guo, and Y. Liu, "Experimental study of the shear strength of soil from the Heifangtai platform of the Loess Plateau of China," Journal of Soils and Sediments, vol. 19, no. 10, pp. 3463-3475, 2019.

[21] Y. Luo, T. H. Wang, X. J. Liu, and H. Zhang, "Laboratory study on shear strength of loess joint," Arabian Journal for Science and Engineering, vol. 39, no. 11, pp. 7549-7554, 2014.

[22] J. J. Wang, J. T. Deng, and S. L. Wu, "Research on shear strength of compacted loess," Applied Mechanics and Materials, vol. 448-453, pp. 1284-1288, 2013.

[23] J. W. Liu, H. H. Fan, X. Y. Song et al., "Characteristics of shear strength and deformation of compacted Q3 loess," Soil Mech Found Engineering, vol. 57, pp. 65-72, 2020.

[24] Y. Li, "A review of shear and tensile strengths of the Malan Loess in China," Engineering Geology, vol. 236, pp. 4-10, 2018.

[25] W. LI, J. Q. Zhuang, and Y. Wang, "Experimental study on influencing factors of shear strength of saturated remolded loess," Journal of Engineering Geology, vol. 26, no. 3, pp. 626-632, 2018.

[26] W. Liu, J. Wang, G. H. Lin et al., "Microscopic mechanism affecting shear strength in lignin-treated loess samples," Advances in Materials Science and Engineering, vol. 2019, Article ID 7126040, 12 pages, 2019.

[27] J. Liang, J. Guo, Y. B. Jiang et al., "Experimental investigation on shear strength parameters of lime stabilized loess," Sustainability, vol. 11, no. 19, p. 5397, 2019.

[28] J. Xu, Y. Li, S. Wang, Q. Wang, and J. Ding, "Shear strength and mesoscopic character of undisturbed loess with sodium sulfate after dry-wet cycling," Bulletin of Engineering Geology and the Environment, vol. 79, no. 3, pp. 1523-1541, 2020.

[29] J. Xu, Y. F. Li, W. Lan et al., "Shear strength and damage mechanism of saline intact loess after freeze-thaw cycling," Cold Regions Science and Technology, vol. 164, pp. 1-13, 2019.

[30] Z. J. Shen, "Science advocates simplicity-some remarks about adopting and methods in geotechnical engineering," Chinese Journal of Geotechnical Engineering, vol. 26, no. 2, pp. 299-300, 2004.

[31] GB/T 50123-2019, Standard for geotechnical test method (in Chinese), China Planning Press, Beijing, China, 2019. 